\title{
How the Global Trade Linkages are Evolving? -Insight from Social Network Analysis Based on Global Multi-Regional Input-Output Model
}

\author{
Kaiyao Wu ${ }^{1}$, Chi Zhou ${ }^{1}$, Dechun Yan $^{2 *}$ \\ ${ }^{1}$ Shanghai University of International Business and Economics, Shanghai 201620, China \\ ${ }^{2}$ Shanghai Lixin University of Accounting and Finance, Shanghai 201209, China \\ E-mail: yan@lixin.edu.cn
}

Received: 7 November 2020; Revised: 5 January 2021; Accepted: 22 January 2021

\begin{abstract}
With the rise and fall of the trade shares of different countries in the world, does the trade network structure change at the same time? Do the dynamics of countries' positions differ in the evolution of trade network structure? Based on the latest world input-output database (WIOD), this paper illustrates the accounting models of international trade, and describes the dynamics of the global trade network structure and the countries' positions. Research shows that China and the emerging countries developed faster than the developed countries during 2000-2014, and play important roles, not only in the trade shares, but also in global trade networks. The innovation of this study is that we present a systemic and explicit portrait of the global pattern of trade linkages between countries based on a set of social network analysis methods, and we find that the dynamic of linkage network is more violative than that of linkage flow.
\end{abstract}

Keywords: multiple-regional input-output model, social network analysis, international trade, global economy

JEL Codes: F14

\section{Introduction}

People argue that the world may have entered a period of global trade slowdown since 2012, that is mostly reasoned out by the volume of international trade. Meanwhile the interconnectedness of the global economy has slowed down the pace of development because of global economy stagnation and anti-globalization in recent years.

Since the global economy is a complex system including so many countries and sectors, which always interact with each other (Albert \& Barabási, 2002; Baldwin \& Lopez-Gonzalez, 2015). It is useful to represent such a complex system as a network, where the nodes (countries and sectors) represent the components and the trade linkages represent their interactions (Buldyrev et al, 2010; Newman, 2018). Since it is the interaction among nodes give rise to the collective behaviors of a network system, many important questions in the complex system can only be addressed by thinking more carefully about interactive network (Lancichinetti, 2011). Previously how to measure economy interaction among countries was talked, indicators of international trade, such as export and import, were emphasized, while the metrics of the network were not.

Input-Output model, initially proposed by Leontief (1936) and further developed by many researchers (Miller \& Blair, 2009), describing the linkages among economic sectors, was extended into multiple regional input-output models

Copyright (C2021 Dechun Yan, et al

DOI: https://doi.org/10.37256/redr.212021714

This is an open-access article distributed under a CC BY license

(Creative Commons Attribution 4.0 International License)

https://creativecommons.org/licenses/by/4.0/ 
(MRIO) as to demonstrate the interaction between regions' sectors. But most of the literatures only used MRIO to derive behavior metrics measuring inter-national linkage flow, such as export and import, the abundant information of interactive network in the MRIO was ignored, leaving the complex system still unknown. Although MRIO and social network analysis (SNA) have become the prevalent methods to analyze international trade or do the analysis in the global perspective in recent years, seldom work was committed to analyze the evolution of the multiple characteristics in the global international trade linkage network through multiple descriptive methods exploring the difference between flow characteristics dynamics and network characteristics dynamics.

We imitated the complex global economy through an international trade linkage network based on Global MultiRegional Input-Output (GMRIO) in this paper, using a set of SNA methods to give some valuable insights of the interactions and network in the complex global economic system.

We think our work can make a good contribution to the literature:

1) This paper studies the systemic and explicit characteristics of the global international trade linkage by using a variety of network descriptive methods, tracking the dynamic of these characteristics over time;

2) This paper demonstrates that the dynamic of network characteristics is quite different from the dynamic of flow characteristics, which is described by descriptive statistics of exports and imports.

Based on the above information, this paper is organized as following: The first section is an introduction; The second section is a literature review of the input output analysis (IOA) and SNA; The third section describes the data and how to process it; The fourth section demonstrates the methodology in the empirical research; The fifth section reports the results and discuss; The last section is a brief conclusion.

\section{Literature review and research questions}

\subsection{Literature review}

Isard (1951) first proposed interregional interaction model to reflect the interdependence between regions through the Interregional input-output matrix. After that researchers used the linkage indicators to measure the quantity and importance of the economical flow between regions, which were indicators measured in the background of the whole economic system. There were mainly three types: a. Direct and complete measurement (Leontief, 1936); b. The backward correlation coefficient and the forward correlation coefficient (Isard, 1951; Beyers, 1976; Heimler, 1991; Cuello et al., 1992); c. Intra-regional effect, inter-regional spillover effect and feedback effect (Lenzen, 2003; Pyatt \& Round, 1978).

Those indicators followed two research directions: a. Demand model (Bar-Yam, 2002; Pyatt \& Round, 1978; Dietzenbacher, 2010); b. Supply model (Zhang, 2017; Ghosh, 1958; Dietzenbacher, 2002). Furthermore, two kinds of trade flows were differentiated in the two mentioned model: a. Standard trade; b. Value added trade. Their inherent relationship was excessively explored (Zhang et al, 2018; Johnson \& Noguera, 2012).

Monarca et al. (2019) used the World Input-Output Database and network analysis (NA) to describe and compare inter-sectoral linkages between manufacturing and other sectors in Italy and China. Cahen-Fourot et al. (2020) built and visualized national inverted pyramid networks, and analyzed their structure by treating Input-Output (IO) data from eighteen European countries as the adjacency matrix of a directed network. The study of Huang (2020) was based on the global value chains theory and social network analysis and constructed the global value networks accounting framework for manufacturing by selecting the data of domestic value-added in exports from 2005 to 2015. Blázquez (2020) explored the phenomenon of international servitization of manufacturing from the period 1995 to 2011 by applying empirical techniques of Social Network Analysis and graph theory.

Although a bunch of work used MRIO and SNA analyze international trade or do the analysis in the global perspective in recent years, there are gaps in two perspectives, which are systemic and explicit picture on the evolution of international linkage network and what is difference between the characteristic of network structure and the one of flow linkage. 


\subsection{Research questions}

Obviously, there are interdependence and interweaving all the time among countries in the global economy, reflecting not only on economical flows between countries but also on a network comprised of countries. In InputOutput framework, SNA and linkage indicators can work side by side to give a complex global economy a more explicit picture, furthermore multiple descriptive methods should be applied to explore systemic and explicit characteristics and track the dynamic of these characteristics over time.

In this paper, we present a portrait of the global pattern of trade linkages between countries. How is this pattern evolving with momentous global economic changes? And what is the difference among countries in this pattern? Which countries were the most important and what were the roles countries have played? These problems were answered with a set of descriptive methods of SNA. We derive linkage indicators and then SNA based on the direct measurement of demand (Leontief, 1936) model.

To explore the differences between the pattern of trade linkages flow and the pattern of trade linkage network, we tracked the development of the flow and the network of international trade linkages, having two hypotheses in mind:

1. Dynamics of the network characteristics are different with that of the flow characteristics.

2. Dynamics of the countries' positions according to trade share is different with the one according to network structure.

\section{Data source and processing}

\subsection{Data source}

Our data source is from the updated World Input-Output Database (WIOD), released in 2016, providing an annual time-series of WIOTs from 2000 to 2014. It covers 43 countries, including all twenty-eight members of the European Union and fifteen other major economies, each country having 56 sectors.

\subsection{Data processing}

To simplify our analysis, we integrated all sectors into one sector for all countries in the research years, that is summing up 56 sectors for each country. We only considered total trade linkage for each bilateral relation so that corresponding network matrixes are derived for countries and years, wherein demand by the country itself is also considered as reflexive flow.

Since the most mature and prevalently used methodologies of social network analysis are with dichotomous network data, we dichotomized each wave of network matrix using the following dichotomization rule:

If $f_{i j}$ is greater than or equal value 64551 , then $f_{i j}=1$, else $f_{i j}=0$, diagonals of the matrix followed dichotomization rule.

The reason of threshold values applied is to obtain the first 100 flows as 1 in the corresponding matrix in 2008, When the recent world economy crisis happened, marking a breakpoint in the world economic progress. 100 flows are selected from total 1892 flows, so that these very large volumes of trade are considered to constitute a connection network, which is the backbone of global international trade. This threshold rule simplifies our network analysis. The same dichotomization rule was applied consistently over time so that the transformed matrixes have a comparable basis for each trade linkage networks.

\section{Method}

\subsection{Linkage indicators}

The global multi-regional input-output accounting framework is shown in Figure 1. 


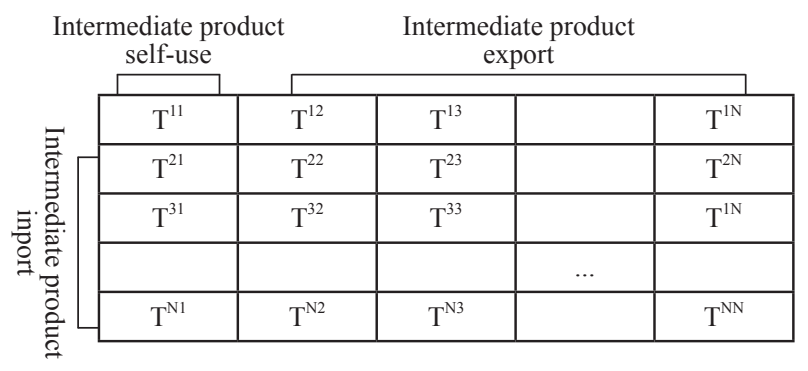

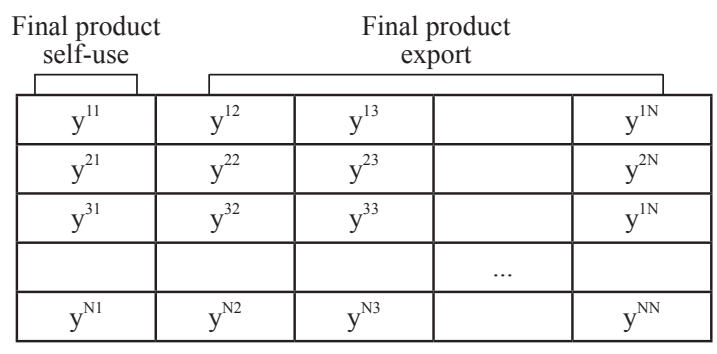

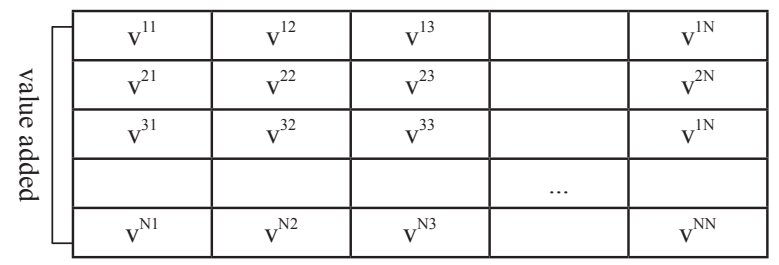

Figure 1. GMRIO framework (The global multi-regional input-output accounting framework shows here is the foundation of GMRIO.)

According to the quantitative relationship between input and output, the total supply of the $s$ region can be expressed as:

$$
x^{s}=T^{s s}+y^{s s}+\Sigma_{r \neq s} T^{s r}+\Sigma_{r \neq s} y^{s r}
$$

The total use of the $s$ region can be expressed as:

$$
z^{s}=T^{s s}+y^{s s}+\Sigma_{r \neq s} T^{r s}+\Sigma_{r \neq s} y^{r s}
$$

So that we can derive followed linkage indicators:

1) Intermediate product export: $\Sigma_{r \neq s} T^{s r}$;

2) Intermediate product import: $\Sigma_{r \neq s} T^{r s}$;

3) Final product export: $\Sigma_{r \neq s} y^{s r}$;

4) Final product import: $\Sigma_{r \neq s} y^{r s}$;

5) Total export: $\Sigma_{r \neq s} T^{s r}+\Sigma_{r \neq s} y^{s r}$;

6) Total import: $\Sigma_{r \neq s} T^{r s}+\Sigma_{r \neq s} y^{r s}$;

7) Intermediate reflexive linkage: $T^{s s}$;

8) Final reflexive linkage: $y^{s s}$;

9) Total reflexive linkage: $T^{s s}+y^{s s}$;

10) Total supply: $x^{s}$;

11) Total use: $z^{s}$.

\subsection{Visualization with MDS}

We used the built-in algorithms, naming 'iterative metric multi-dimensional scaling (MDS)' in NetDraw to generate coordinates based on similarity, adjusted to nearest Euclidean. To clarify major countries' roles, we delete the flows from and to the 'Rest of the World (ROW)'. Because our main intention is to explore the network, we don't change the appearance option to reflect any attribute of nodes, sustaining default neat style.

\subsection{Triad census}

In triad census, dyads configurations are certainly monitored. As shown in Table 3, 16 possible triadic 
configurations of directed non-reflexive graph are counted up. Type 003 (hereafter referred to 'category I') is actually a combination of 3 unconnected nodes or 3 null dyads. Type 012 is actually for asymmetric dyads, while Type 102 is actually for mutual dyads (these two-hereafter referred to 'category II'). Others including in-star, out-star, transitive and intransitive triads are all having not less than 2 links to bond 3 nodes (hereafter referred to 'category III').

\subsection{Cohesion metrics characterizing the whole network}

With these Cohesion metrics measuring the whole network, we intended to measure how nodes in a network are strongly or closely related to each other according to cohesion approach. As shown in Table 3, these 5 metrics are positive and are based on 'dyad' which is simply the relation between two nodes. Their conception and formula are demonstrated below. In this paper, their value is calculated with UCINET, ignoring reflexive links but not ignoring the direction of links (if the direction is applied in the formula).

1) Avg Degree $A D(t), 0 \leq A D(t) \leq n-1$, is the average degree in the underlying graph, which is most simple metric of cohesion.

$$
A D=\frac{\sum_{i} \sum_{i j} d_{i j}(t)}{n}
$$

Where degree $d_{i j}(t)$ values 1 if link exits between node $i$ and $j$ in the period $t$, and values 0 if no link exits.

2) Density $\delta(t)$, with $0 \leq \delta(t) \leq 1$, is the number of links divided by the maximum number possible (the elements on the diagonal are ignored).

$$
\delta(t)=\frac{\sum_{i} \sum_{i j} d_{i j}(t)}{n(n-1)}
$$

3) Connectedness $C N(t)$, with $0 \leq C N(t) \leq 1$, is defined as the proportion of pairs of nodes that can reach each other by a path of any length. It can be calculated by 1 minus the fragmentation which is a proportion of pairs of nodes that are unreachable.

$$
C N(t)=1-\frac{V}{n(n-1)}
$$

Where $V$ is pairs of nodes that are unreachable.

4) Compactnessis $C P(t)$, with $0 \leq C P(t) \leq 1$, is distance-based cohesion metric weighting the path connecting nodes inversely by their length. It has a value of 1 when the network is a clique (everyone is adjacent) and zero when the network is entirely made up of isolated nodes.

$$
C P(t)=\frac{\sum_{(i \neq j)}\left[1 / g_{i j}(t)\right]}{n(n-1)}
$$

Where $g_{i j}(t)$ is the geodesic distance from $i$ to $j$, and $1 / g_{i j}(t)$ is set to 0 when no path exists from $i$ to $j$.

5) Deg Centralization $C(t)$, with $0 \leq C(t) \leq n-1$, is calculated based on the conception of Degree Centrality (see below) by applying equation (6), regardless of supply/demand directionality.

$$
C(t)=\frac{\sum_{j}\left(C_{j *}(t)-C_{j}(t)\right)}{(n-1)^{2}}
$$

The first four are metrics based on cohesion approach so that they are pure cohesion metrics; the fifth one measures 
the extent the whole network is dominated by a single node according to position approach, with a mixture nature, telling cohesion characteristics based on position approach, thus they are cohesion metric blended with position information.

\subsection{Position metric: degree centrality}

Cohesion metrics characterizing the whole network provide single numbers to describe concerned aspects of the network but tell nothing about how nodes and links are distributed. Degree Centrality is actually a measure of node's position in the whole network. In a direct graph, the row sums of the adjacency matrix are denoted as indegree

$$
D C_{i}^{i n}(t)=\sum_{j(j \neq i)} d_{i j}(t)
$$

with $0 \leq D C_{i}^{i n}(t) \leq n-1$;

the column sums are denoted as outdegree

$$
D C_{i}^{\text {out }}(t)=\sum_{j(j \neq i)} d_{i j}(t)
$$

with $0 \leq D C_{i}^{\text {out }}(t) \leq n-1$.

\subsection{Core-Periphery Model}

This model is to partition nodes into two groups (core and periphery) based on position equivalent of them (Hanneman and Riddle, 2005). The fundamental idea underlying the notion of position equivalent is that of structural correspondence or similarity. With the Core-Periphery Model, we are able to include both the idea of relation between two core members and the idea of internal equivalent as well as the idea of a separation from members outside the core. The pattern of core-periphery can be seen in the block-model shown Table 3: There are 4 blocks in the Class Blocked Adjacency Matrix, as core, core-periphery, periphery-core and periphery. Since nodes which are position equivalent would exhibit similar behaviors and outcomes, the partitioning of core nodes and periphery nodes has meaningful policy implication. In this paper, we use the discrete core-periphery method in UCINET based on partition criterion of degree centrality and correlation fitness measure.

\subsection{Dynamic tracking}

\subsubsection{Sequential growth rate}

For tracking the general characteristics of trade flow and network: At the first initiative, we tend to use the descriptive metrics, such as mean and standard deviation of mean of export and import, to compare with the descriptive metrics of trade network. But they can not be directly compared because of different dimension. We then use sequential growth rate sequential growth rate (SGR) of each descriptive metric and compare their value and dynamic routine.

$$
S G R=\left(M_{t}-M_{t-1}\right) / M_{t-1}
$$

Where $M_{t}$ is descriptive metric at ' $t$ ' period, $M_{t-1}$ is descriptive metric at ' $t-1$ ' period.

\subsubsection{Rank-change chart}

For tracking the position of countries: we sort the countries in descending order according to the trade volume and Degree Centrality of countries separately, get their ranks in each year and map time-based multiline chart. 


\section{Results and discussion}

\subsection{The evolution of trade linkages}

As shown in Figure 2, most countries almost experienced a long term of development, except an apparent regression in this long term of development, except an apparent regression in the year 2009, just after the world economic crisis. In the early 21st century, USA was the top one of total export and of total import. In 2007 and 2008, DEU surpassed the USA with a small amplitude. After 2009, CHN became the first total export country, followed by USA and DEU. Although CHN's total import increased quickly after 2010, it just wined DEU and had the second position. JPN, GBR, FRA, KOR and NLD were other giants in both export and import, although they experienced a mild fluctuation in the period of 2000-2014.

In terms of the proportion of the world, CHN and ROW were both powers of rapid growth. In the case of export, $\mathrm{CHN}$ had more rapid growth than ROW. In the case of import, CHN and ROW almost parallel advanced. The other giants mostly experienced shrink with different fluctuation. The world economic crisis did have transient effects but did not influence long-term trends.

Figure 4 is based on the total scale of import and export trade in various countries. It shows that China and some emerging developing countries are growing strongly and playing an important role in the international trade map, while traditional trading powers still occupy the forefront.
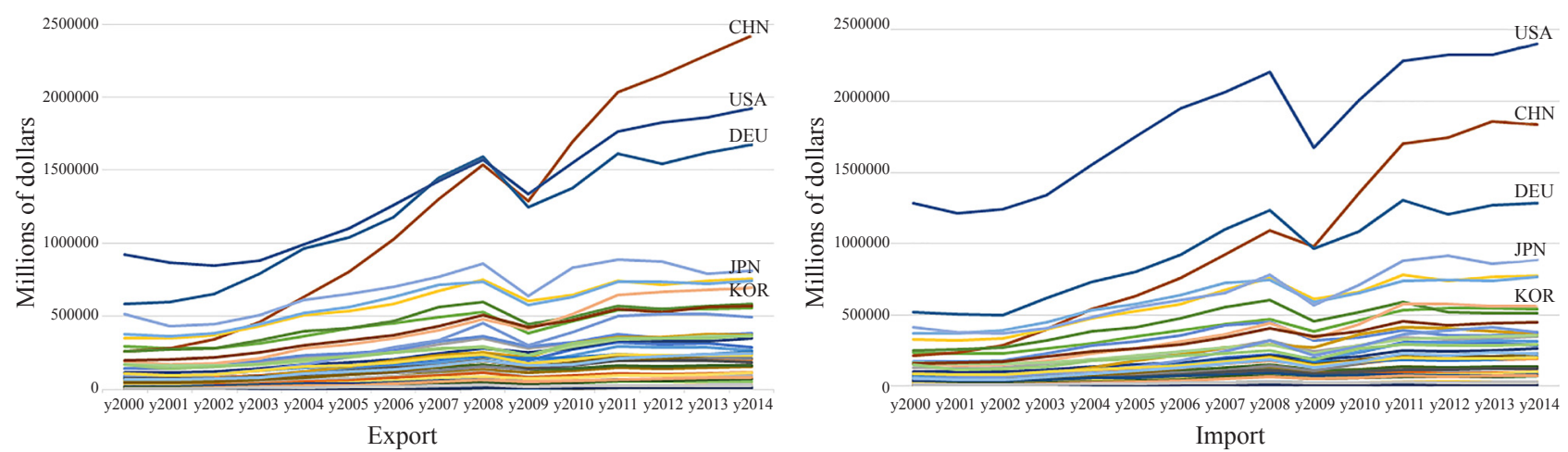

A. Trade volume
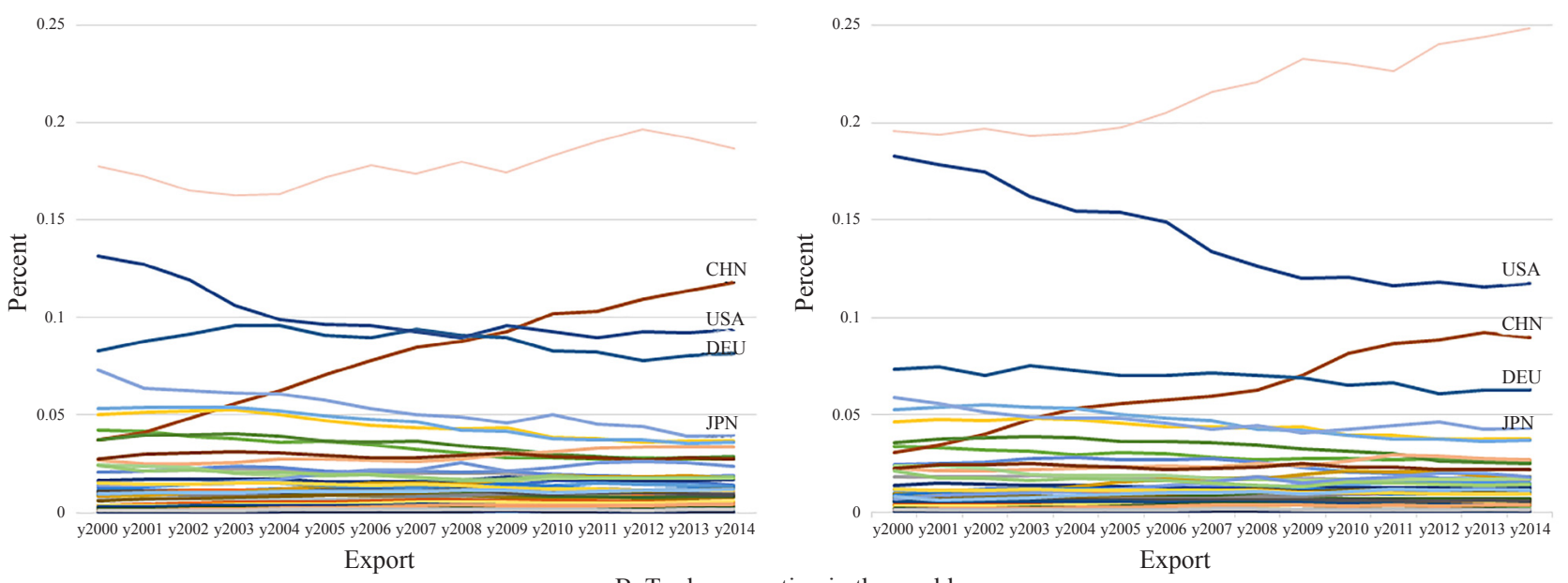

B. Trade proportion in the world

Figure 2. Total export and total import of countries (The evolution of total bilateral linkages is shown based on scale indicators (A) and proportional indicators (B) of export and import.) 


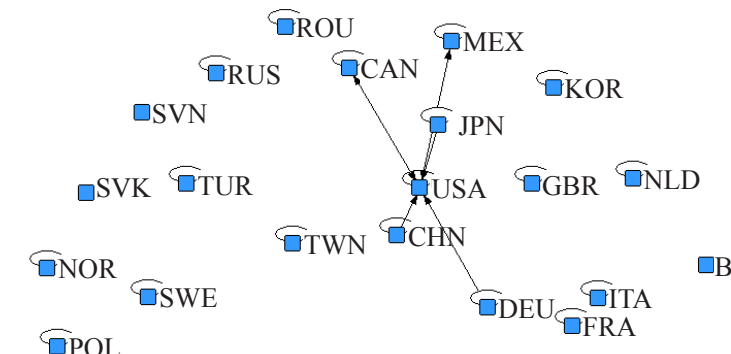

GPOL GBR

GIRL

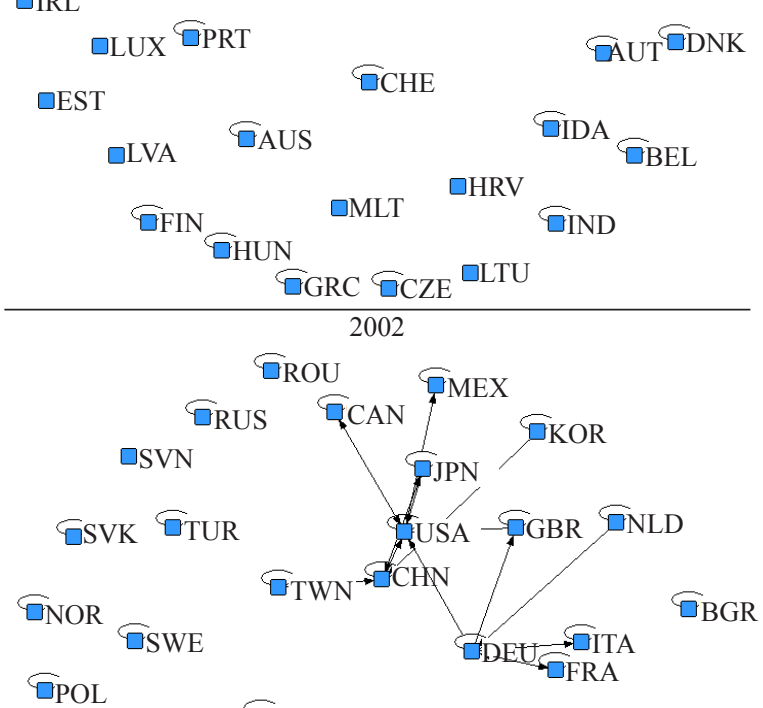

बPOL
बIRL

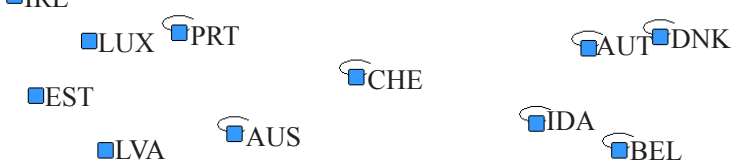

$$
\begin{aligned}
& \text { aLva बaus बida } \\
& \text { बFIN }_{\sigma_{H U N}} \text { aMLT }{ }^{\text {QHRV }} \text { बIND }
\end{aligned}
$$$$
\Xi_{G R C} \Phi_{C Z E}{ }^{\text {LLTU }}
$$$$
\text { GROU }{ }^{2006} \text { बMEX }
$$

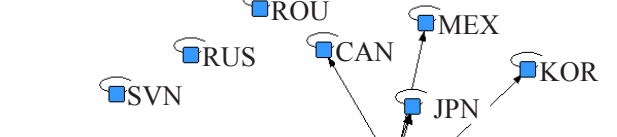$$
\text { बSVK פTUR }
$$

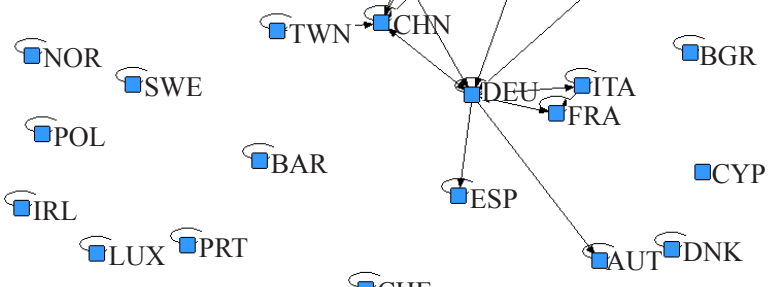

$$
\text { GuUx बPRT }
$$$$
\text { aEST } \sigma_{\text {CHE }}
$$

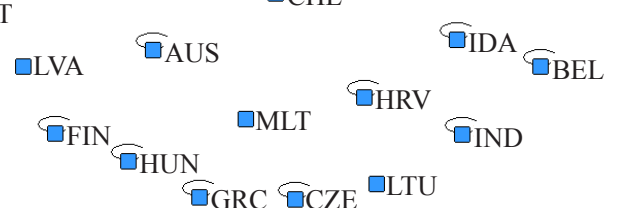$$
2008
$$

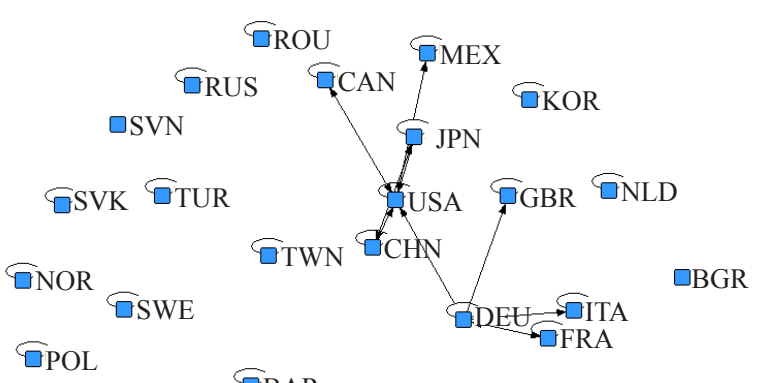

Girl GBAR Gesp

$$
\text { aLUX GPRT }
$$$$
\text { बESTE }
$$

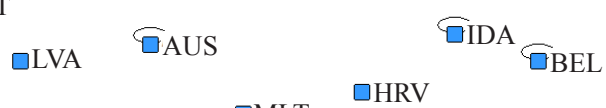

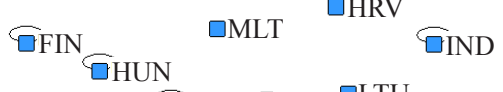$$
\text { बGRC } \text { QCZE }^{\square L T U}
$$
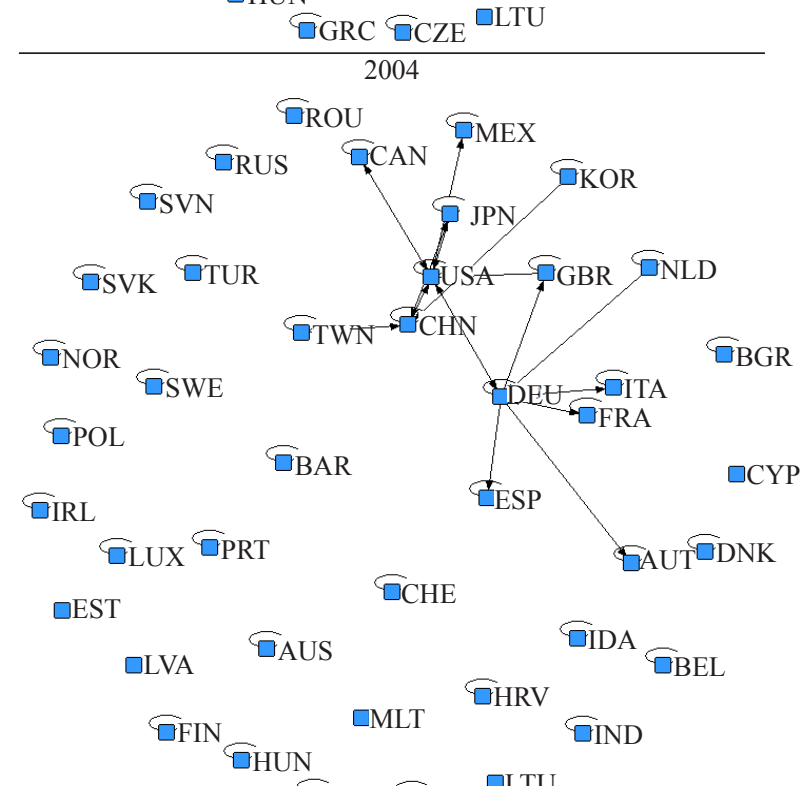
बGRC बCZE

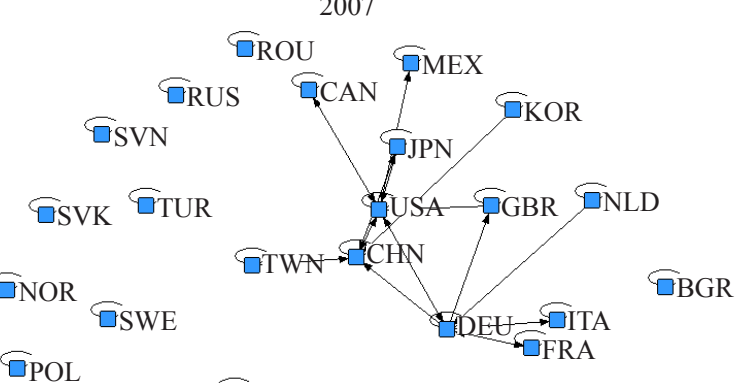

बPOL

OIRL EESP

GLUX बPRT बAUT

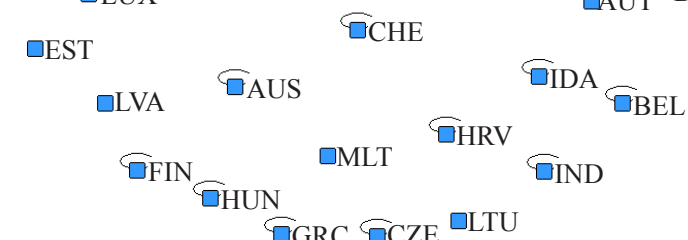
2009 


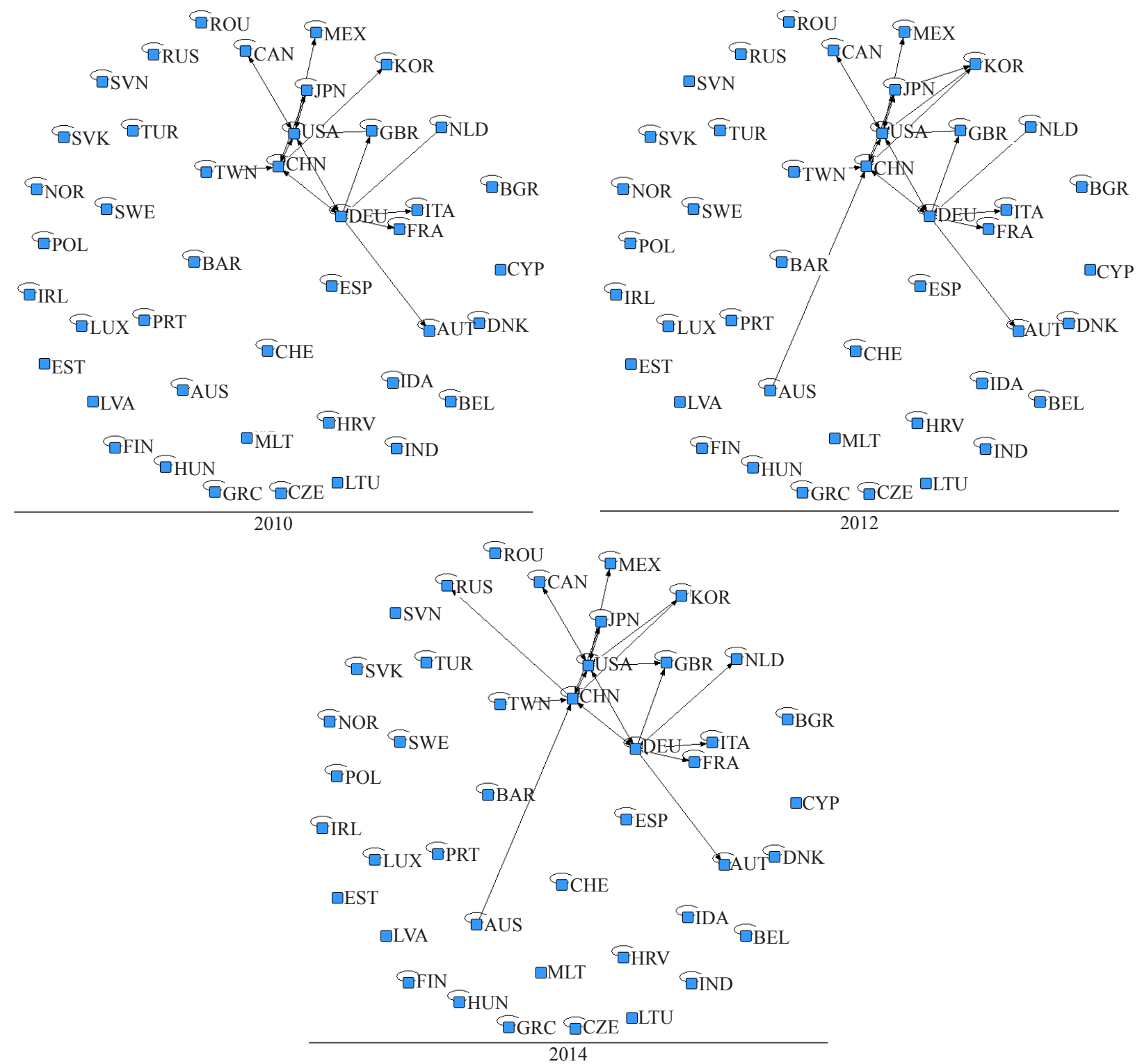

Figure 3. Network visualization (This visualization is realized using the built-in algorithm iterative metric multi-dimensional scaling (MDS) in NetDraw to generate coordinates based on similarity and adjusted to the nearest Euclidean.)

\subsection{Network visualization}

From the visualization with MDS in NetDraw (shown in Figure 3), it is apparent that: The matrix is very sparse; most reflexive linkages are significant; very few bilateral flows are significant on a global scale; USA was always the first developed regional core of regional bilateral flows and the significant core of global bilateral flows; CHN along with DEU were the significant core of the regional bilateral flows; the core members had frequently significant bilateral flows; regional giants, such as JPN, GBR, had significant bilateral flows with the regional core as well as the global core. The global economic crisis decreased the frequency of global bilateral flows, especially the one from or to the USA, but it was gradually recovered just after 2009 .

Because the network we designed represents the backbone of global international trade, the global economic crisis is apparently manifested by the dynamic of this network. Meanwhile the network structure demonstrates some important trends of global international trade, such as regionalization, the decline of US trade status and the rise of China. 
The relative importance of countries in the trade backbone network and their evolution over time are obviously different from that shown in Figure 2, which is based on the scale of import and export trade of each country. More importantly, the trade backbone network provides information on connections between countries that are not available in Figure 2.

\subsection{Triad census}

As shown in Table 1, the values of four pure cohesion metrics (Avg Degree, Density, Connectedness and Compactness) were increasing from 2000 to 2008, they all experienced a transitorily drop from 2008 to 2009 , and then regained increasing. It means that the extend of cohesion is almost increasing except the global economic crisis had interrupted. Deg Centralization has a slight difference with a maximum in 2012 and subsequent decline. Since it means the extend of the whole network dominated by a single node, its dynamic shows the trend of multiploidization in the trade backbone network.

\section{Table 1. Triad census}

\begin{tabular}{cccc}
\hline & category I & category II & category III \\
\hline y2000 & $97.0 \%$ & $2.8 \%$ & $0.2 \%$ \\
y2002 & $96.7 \%$ & $3.1 \%$ & $0.2 \%$ \\
y2004 & $95.0 \%$ & $4.6 \%$ & $0.3 \%$ \\
y2006 & $92.9 \%$ & $6.4 \%$ & $0.7 \%$ \\
y2007 & $91.5 \%$ & $7.3 \%$ & $1.2 \%$ \\
y2008 & $90.4 \%$ & $7.9 \%$ & $1.7 \%$ \\
y2009 & $91.4 \%$ & $7.2 \%$ & $1.4 \%$ \\
y2010 & $91.0 \%$ & $7.4 \%$ & $1.6 \%$ \\
y2012 & $90.0 \%$ & $8.2 \%$ & $1.8 \%$ \\
y2014 & $89.8 \%$ & $8.1 \%$ & $2.0 \%$ \\
\hline
\end{tabular}

Note: category I include:

1. $003=\mathrm{A}, \mathrm{B}, \mathrm{C}$, the empty subgraph. category II include:

2. $012=\mathrm{A}->\mathrm{B}, \mathrm{C}$, subgraph with a single directed edge.

3. $102=\mathrm{A}<->\mathrm{B}, \mathrm{C}$, the subgraph with a mutual connection between two nodes. category III include:

4. $021 \mathrm{D}=\mathrm{A}<-\mathrm{B}->\mathrm{C}$, the out-star.

5. $021 \mathrm{U}=\mathrm{A}->\mathrm{B}<-\mathrm{C}$, the in-star.

6. $021 \mathrm{C}=\mathrm{A}->\mathrm{B}->\mathrm{C}$, directed line.

7. $111 \mathrm{D}=\mathrm{A}<->\mathrm{B}<-\mathrm{C}$.

8. $111 \mathrm{U}=\mathrm{A}<->\mathrm{B}->\mathrm{C}$

9. $030 \mathrm{~T}=\mathrm{A}->\mathrm{B}<-\mathrm{C}, \mathrm{A}->\mathrm{C}$.

10. $030 \mathrm{C}=\mathrm{A}<-\mathrm{B}<-\mathrm{C}, \mathrm{A}->\mathrm{C}$.

11. $201=\mathrm{A}<->\mathrm{B}<->\mathrm{C}$.

12. $120 \mathrm{D}=\mathrm{A}<-\mathrm{B}->\mathrm{C}, \mathrm{A}<->\mathrm{C}$.

13. $120 \mathrm{U}=\mathrm{A}->\mathrm{B}<-\mathrm{C}, \mathrm{A}<->\mathrm{C}$.

14. $120 \mathrm{C}=\mathrm{A}->\mathrm{B}->\mathrm{C}, \mathrm{A}<->\mathrm{C}$

15. $210=\mathrm{A}->\mathrm{B}<->\mathrm{C}, \mathrm{A}<->\mathrm{C}$.

16. $300=\mathrm{A}<->\mathrm{B}<->\mathrm{C}, \mathrm{A}<->\mathrm{C}$, complete subgraph.

$9,12,13,16$ are transitive; $6,7,8,10,11,14,15$ are intransitive

\subsection{Dynamics of cohesion metrics}

As shown in Table 2, the value of four pure cohesion metrics (Avg Degree, Density, Connectedness and Compactness) and of Deg Centralization was increasing from 2000 to 2008, they all experienced a transitorily drop from 2008 to 2009, and then regained increasing. It means that the extend of cohesion and the extend of the whole network dominated by a single node was almost increasing except the economic crisis. 
Table 2. Metrics of Cohesion (Using the software of UCINET, the value of these 5 cohesion metrics are derived from 2002 to 2014 .)

\begin{tabular}{cccccccccc}
\hline & y2002 & y2004 & y2006 & y2007 & y2008 & y2009 & y2010 & y2012 & y2014 \\
\hline Avg Degree & 0.386 & 0.614 & 0.886 & 1.136 & 1.386 & 1.091 & 1.318 & 1.477 & 1.500 \\
Deg Centralization & 0.088 & 0.131 & 0.222 & 0.289 & 0.332 & 0.241 & 0.358 & 0.378 & 0.353 \\
Density & 0.009 & 0.014 & 0.021 & 0.026 & 0.032 & 0.025 & 0.031 & 0.034 & 0.035 \\
Connectedness & 0.030 & 0.058 & 0.096 & 0.153 & 0.192 & 0.134 & 0.201 & 0.223 & 0.233 \\
Compactness & 0.018 & 0.033 & 0.056 & 0.086 & 0.108 & 0.077 & 0.112 & 0.125 & 0.129 \\
\hline
\end{tabular}

\subsection{Evolution of countries'position}

Based on formula (8), (9), we derived the metrics of countries' position in the 15 waves of trade linkage network, which are illustrated in Figure 4.
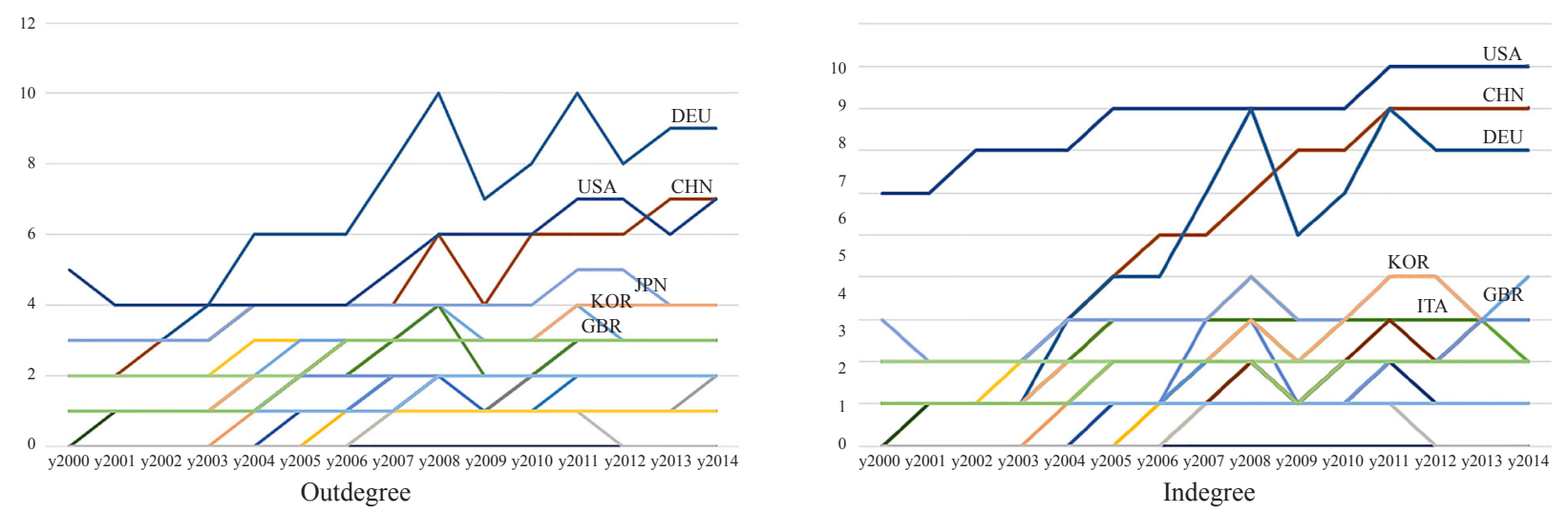

Figure 4. Degree centrality (The evolution of countries' degree centrality are shown separately by outdegree and indegree.)

As for outdegree (shown in the left of the Figure 4), DEU, USA, CHN, JPN, KOR, GBR were the 6 biggest countries after 2010 while AUS, CAN, FRA, ITA, NLD and TWN were other important players who had 3 outdegree. DEU sustained the top position after 2003, whose export was under 2nd position according to trade scale. China was the second or the third player according to outdegree after 2009, while China was the top exporter during the same period. USA only took the third after the global economic crisis, while USA was the second exporter during the same period.

As for indegree (shown in the right of the Figure 4), USA, CHN, DEU, GBR, FRA, ITA were the 6 biggest countries after 2003, JPN, KOR, NLD, RUS were other important players. USA had the largest number of indegree as well as import in the research period. CHN, DEU were the second or the third player, their exact position were not the same as the one according to the important scale.

In general, the most important players listed in the backbone network were not the countries who had the largest export or import, showing another story of international trade.

\subsection{Core-periphery analysis}

The correlation between the Class Blocked Adjacency matrix and the idealized block structure (fitness) respectively was more than 0.77 from 2000 to 2014, indicating a fairly good core-periphery structure. Class Blocked Adjacency Matrixes and Density Matrixes indicate that different network behavior of countries was ascribed to different countries' position in the network. 
Class Blocked Adjacency Matrixes show: USA was always in the core; JPN was in the core in 2004, 2008,2011 and 2012; CHN was in the core after 2002; DEU was in the core after 2003.

The core blocks have a density of more than 0.67 , and the peripheral blocks have a density of less than 0.001 , indicating that core countries supply other core countries and peripheral countries do not supply other peripheral countries. The core-periphery structure is further reinforced by examining the two off-diagonal blocks. It shows intermediate product linkages were most between members from core-core, then from periphery-core, and then from core-periphery, very few from periphery-periphery.

Table 3. Core-periphery analysis (Based on our core-periphery analysis, final fitness of core-periphery model, countries in the core block and density of four blocks in each year are shown here for three types of linkage)

\begin{tabular}{|c|c|c|c|c|c|c|c|c|c|}
\hline & \multirow{2}{*}{ Final fitness } & \multirow{2}{*}{\multicolumn{4}{|c|}{ core }} & \multicolumn{4}{|c|}{ Density } \\
\hline & & & & & & $\mathrm{c}-\mathrm{c}$ & c-p & p-c & $\mathrm{p}-\mathrm{p}$ \\
\hline 2000 & 1 & USA & ROW & & & 1 & 0.2 & 0.188 & 0 \\
\hline 2001 & 1 & USA & ROW & & & 1 & 0.2 & 0.181 & 0 \\
\hline 2002 & 1 & USA & ROW & & & 1 & 0.1 & 0.181 & 0.001 \\
\hline 2003 & 0.833 & USA & ROW & $\mathrm{CHN}$ & & 1 & 0.2 & 0.188 & 0.001 \\
\hline 2004 & 0.815 & USA & ROW & $\mathrm{CHN}$ & DEU & 1 & 0.1 & 0.156 & 0 \\
\hline 2005 & 0.815 & USA & ROW & $\mathrm{CHN}$ & DEU & 0.92 & 0.1 & 0.144 & 0 \\
\hline 2006 & 0.815 & USA & ROW & $\mathrm{CHN}$ & DEU & 0.92 & 0.1 & 0.162 & 0.001 \\
\hline 2007 & 0.865 & USA & ROW & $\mathrm{CHN}$ & DEU & 0.75 & 0.1 & 0.144 & 0 \\
\hline 2008 & 0.916 & USA & ROW & $\mathrm{CHN}$ & DEU & 0.67 & 0.1 & 0.112 & 0 \\
\hline 2009 & 0.957 & USA & ROW & $\mathrm{CHN}$ & DEU & 0.67 & 0.1 & 0.094 & 0 \\
\hline 2010 & 1 & USA & ROW & $\mathrm{CHN}$ & DEU & 0.67 & 0.1 & 0.063 & 0 \\
\hline 2011 & 0.96 & USA & ROW & $\mathrm{CHN}$ & DEU & 0.83 & 0 & 0.065 & 0.001 \\
\hline 2012 & 0.96 & USA & ROW & $\mathrm{CHN}$ & DEU & 1 & 0.1 & 0.119 & 0 \\
\hline 2013 & 1 & USA & ROW & $\mathrm{CHN}$ & DEU & 1 & 0.1 & 0.107 & 0 \\
\hline 2014 & 1 & USA & ROW & $\mathrm{CHN}$ & DEU & 1 & 0.1 & 0.107 & 0 \\
\hline
\end{tabular}

\subsection{Comparing the flow dynamics and the network dynamics}

\subsubsection{Dynamics of the general characteristics}

For bilateral trade flow, the volumes of import and export were considered here; to describe their statistical feature, we used mean and standardized deviation of mean, so we have 4 descriptive metrics, which are imMean, imStdMean, exMean and exStdMean. For trade network, we used Avg degree, Deg centralization, density, connectedness and compactness as showed in the section 4.4. Their SGRs were calculated and mapped in a multiple-lines chart as showed in Figure 5.

Although all SGRs have similar trend, decreasing from a positive value to a negative in 2009, and then restoring to positive growth which rates are decreasing from 2010. The SGRs of network cohesions are more turbulent than that of bilateral trade flow.

\subsubsection{Dynamics of the country' positions}

We used the technique showed in section 5.7 to get the countries' ranks according to their trade shares and degree 
centralities. In general, the specific country's rank in the network structure is quite different with the one in trade shares, and the former is more unstable than the latter over time. To clarify, 5 countries' data is draw and mapped into multiplelines to show their dynamic change. Comparing import and indegree, although USA has the first rank in the research period no matter which rule is applied, CHN, CAN, DEU and MEX have different ranks respectively according to different rule, and the rank dynamics of each country has more volatility in the left chart because of 'network' rule is applied. Comparing export and outdegree, the similar conclusion could be made, except the position of USA is not always the first and has different manifestations in different rules.

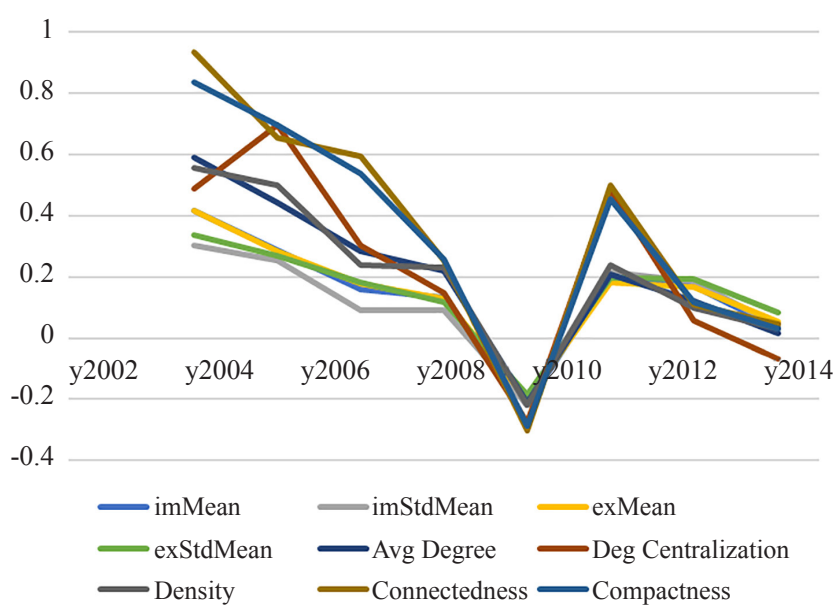

Figure 5. SGRs of descriptive metrics (The SGRs of network cohesions are more turbulent than that of bilateral trade flow.)

\section{Conclusion}

In this paper, we combined the methodologies of linkage indicators and SNA in the Input-Output framework to give the global trade pattern a more systemic and explicit picture, based on the 15 waves (years) of trade linkage networks. Linkage indicators, export and import, were calculated, then a static and dynamic comparison of these indicators was carried out. The evolvement of total bilateral trade linkage networks was extensively explored and analyzed, respectively from monoliths/global and node/country level, using the SNA method of network visualization, triad census, cohesion metrics, position metric and core-periphery model.

We found out that global economic flows were developed continually from 2000 to 2014, except the year of the world economic crisis which caused a reduction transitorily. Although the USA and west countries remained the dominant role, China and emerging countries had more rapid development and already played important roles. China had become the major giant driving the development of global trade flows, and it had become the first exporter of final product and total product. From our social network analysis, the density, connectedness and compactness of linkage networks were increasing over time except for the year after the world crisis, while the dynamic of countries' role in the trade linkage networks also show their importance rise and fall. The most significant change is the position of China in the world trade network because the trade linkages from and to it increased dramatically in this research period. We have a novel finding: the dynamics of network structure is quite more volatile than the dynamics of linkage flow, which is manifested in both the whole network and countries' position in it. In this case, network volatility is more sensibility to economic crisis than trade volume development, which has remarkable meaning to economic researchers and policy makers.

Overall, we traced the evolvement of the complex global economic system through the approach of linkage indicator and SNA. We demonstrated the phenomena but did not disclose the mechanism behind this phenomenon. In future research, more work needs to be focused on the mechanism to better understand the complex global economic system and raise a better solution to the challenge of the global economy. 

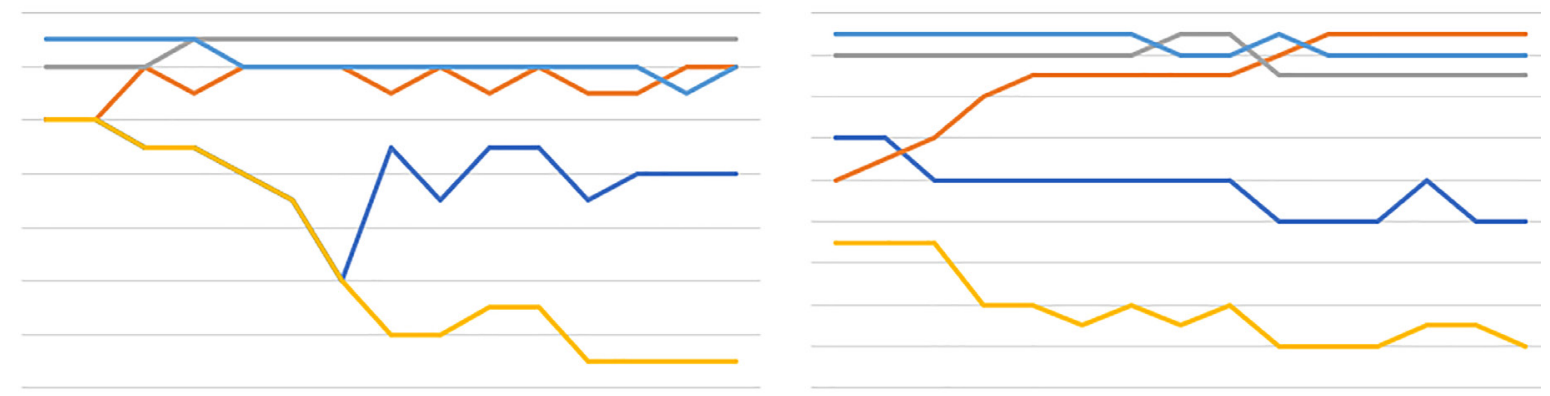

$\longrightarrow \mathrm{CAN} \longrightarrow \mathrm{CHN} \longrightarrow \mathrm{DUE}-\mathrm{MEX} \longrightarrow \mathrm{USA}$ A. Dynamic of export rank and outdegree rank $\longrightarrow \mathrm{CHN} \longrightarrow \mathrm{DUE} \longrightarrow \mathrm{MEX} \longrightarrow \mathrm{USA}$

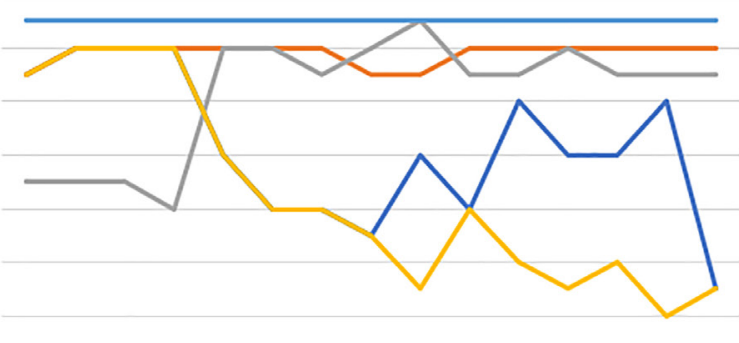

$\longrightarrow$ CAN $\longrightarrow$ CHN $\longrightarrow$ DUE $\longrightarrow$ MEX $\longrightarrow$ USA

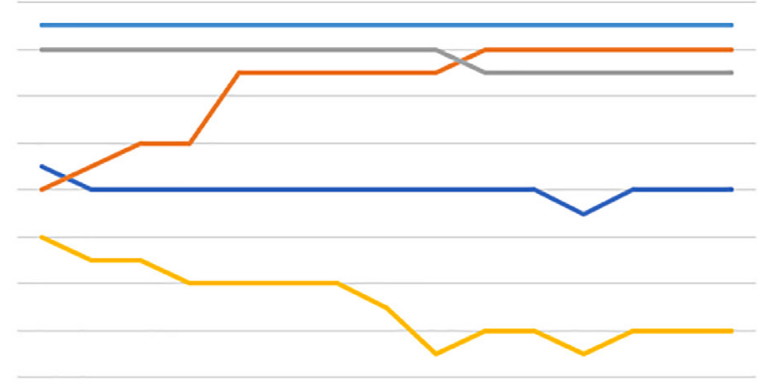

$\longrightarrow$ CAN $\longrightarrow$ CHN $\longrightarrow$ DUE $\longrightarrow$ MEX $\longrightarrow$ USA

B. Dynamic of import rank and indegree rank

Figure 6. The dynamics of countries' rank (The rank position of country in right chart of A is according to the volume of export; the one in left chart of $\mathrm{A}$ is according to the outdegree in corresponding network; the one in right chart of $\mathrm{B}$ is according to the volume of import; the one in left chart of $\mathrm{B}$ is according to the indegree in corresponding network)

Table 4. Abbreviations of countries' name (This table lists countries' names and their abbreviations in the WIOD dataset.)

\begin{tabular}{|c|c|c|c|c|c|}
\hline & ISO & Country & & ISO & Country \\
\hline 1 & AUS & Australia & 23 & IRL & Ireland \\
\hline 2 & AUT & Austria & 24 & ITA & Italy \\
\hline 3 & BEL & Belgium & 25 & JPN & Japan \\
\hline 4 & BGR & Bulgaria & 26 & KOR & Korea \\
\hline 5 & BRA & Brazil & 27 & LTU & Lithuania \\
\hline 6 & CAN & Canada & 28 & LUX & Luxembourg \\
\hline 7 & $\mathrm{CHE}$ & Switzerland & 29 & LVA & Latvia \\
\hline 8 & $\mathrm{CHN}$ & China & 30 & MEX & Mexico \\
\hline 9 & CYP & Cyprus & 31 & MLT & Malta \\
\hline 10 & $\mathrm{CZE}$ & Czech Republic & 32 & NLD & Netherlands \\
\hline 11 & DEU & Germany & 33 & NOR & Norway \\
\hline 12 & DNK & Denmark & 34 & POL & Poland \\
\hline 13 & ESP & Spain & 35 & PRT & Portugal \\
\hline 14 & EST & Estonia & 36 & $\mathrm{ROU}$ & Romania \\
\hline 15 & FIN & Finland & 37 & RUS & Russia \\
\hline 16 & FRA & France & 38 & VK & Slovak Republic \\
\hline 17 & GBR & United Kingdom & 39 & SVN & Slovenia \\
\hline 18 & GRC & Greece & 40 & SWE & Sweden \\
\hline 19 & HRV & Croatia & 41 & TUR & Turkey \\
\hline 20 & HUN & Hungary & 42 & TWN & Taiwan \\
\hline 21 & IDN & Indonesia & 43 & USA & United States \\
\hline 22 & IND & India & & & \\
\hline
\end{tabular}




$$
\begin{aligned}
& -\mathrm{AUS}-\mathrm{AUT}-\mathrm{BEL}-\mathrm{BGR}-\mathrm{BRA}-\mathrm{CAN}-\mathrm{CHE}-\mathrm{CHN}-\mathrm{CYP}-\mathrm{CZE}-\mathrm{DEU} \\
& \text {-DNK -ESP }- \text { EST }- \text { FIN }- \text { FRA }- \text { GBR }- \text { GRC }- \text { HRV }- \text { HUN }- \text { IDN } \\
& \text {-IRL -ITA - JPA }- \text { KOR - LTU }- \text { LUX }- \text { LVA }- \text { MEX }-\mathrm{MLT} \longrightarrow \mathrm{NLD}-\mathrm{DOR} \\
& -\mathrm{POL}-\mathrm{PRT}-\mathrm{ROU}-\mathrm{RUS}-\mathrm{SVK}-\mathrm{SVN}-\mathrm{SWE}-\mathrm{RUR}-\mathrm{TWN}-\mathrm{USA} \longrightarrow \text { ROW }
\end{aligned}
$$

\section{Acknowledgements}

This project is supported by the National Social Science Foundation of China (Grant No.20BTJ014).

\section{References}

Albert, R., \& Barabási, A. L. (2002). Statistical mechanics of complex networks. Reviews of modern physics, 74(1), 4797. https://doi.org/10.1103/RevModPhys.74.47

Baldwin, R., \& Lopez-Gonzalez, J. (2015). Supply-chain trade: A portrait of global patterns and several testable hypotheses. The World Economy, 38(11), 1682-1721. https://doi.org/10.1111/t wec.12189

Bar-Yam, Y. (2002). General features of complex systems. Encyclopedia of Life Support Systems. UNESCO, EOLSS Publishers.

Beyers, W. B. (1976). Empirical identification of key sectors: Some further evidence. Environment and Planning A, 8(2), 231-236. https://doi.org/10.1068/a080231

Blázquez, L., Díaz-Mora, C., \& González-Díaz, B. (2020). The role of services content for manufacturing competitiveness: A network analysis. Plos one, 15(1), e0226411. https: //doi.org /10.1371/ journal. pone.0226411

Buldyrev, S. V., Parshani, R., Paul, G., Stanley, H. E., \& Havlin, S. (2010). Catastrophic cascade of failures in interdependent networks. Nature, 464, 1025-1028. https://www. nature.com/ articles/nature08932

Cahen-Fourot, L., Campiglio, E., Dawkins, E. Godin, A., \& Kemp-Benedict, E. (2020). Looking for the inverted pyramid: An application using input-output networks. Ecological Economics, 169, 106554. https://doi.org/10.1016/ j.ecolecon.2019.106554

Cuello, F. A., Mansouri, F., \& Hewings, G. J. D. (1992). The identification of structure at the sectoral level: A reformulation of the Hirschman-Rasmussen key sector indices. Economic Systems Research, 4(4), 285-296. https:// doi.org/10.1080/09535319200000027

Dietzenbacher, E. (2002). In vindication of the ghosh model: A reinterpretation as a price model. Journal of Regional Science, 37(4), 629-651. https://doi.org/10.1111/0022-4146.00073

Dietzenbacher, E. (2010). Interregional multipliers: Looking backward, looking forward. Regional Studies, 36(2), $125-$ 136. https://doi.org/10.1080/00343400220121918

Ghosh, A. (1958). Input-output approach in an allocation system. Economica, 25(97), 58-64. https://doi. org/10.2307/2550694.

Hanneman R. A., \& Riddle, M. (2005). Introduction to social network methods. Riverside, CA: University of California. http:// faculty.ucr.edu/ hanneman/

Heimler, A. (1991). Linkages and vertical integration in the Chinese economy. The Review of Economics and Statistics, 73(2), 261-267. https://doi.org/10.2307/2109516

Huang, G. (2020). Global value networks of manufacturing: Accounting framework, power centers and world images. Power Centers and World Images. http://dx.doi.org/10.2139/ssrn. 3596041 
Isard, W. (1951). Interregional and regional input-output analysis: A model of a space-economy. The review of Economics and Statistics, 33(4), 318-328. https://doi.org/10.2307/1926459

Johnson, R. C., \& Noguera, G. (2012). Accounting for intermediates: Production sharing and trade in value added. Journal of international Economics, 86(2), 224-236. https://doi.org/10.1016/j.jinteco.2011.10.003

Lancichinetti, A., Radicchi, F., Ramasco, J. J., \& Fortunato, S. (2011). Finding statistically significant communities in networks. PloS one, 6(4), e18961. https://doi.org/10.1371/journal.pone.0018961

Lenzen, M. (2003). Environmentally important paths, linkages and key sectors in the Australian economy. Structural Change and Economic Dynamics, 14(1), 1-34. https://doi.org/10.1016/S0954-349X(02)00025-5

Leontief, W. W. (1936). Quantitative input and output relations in the economic systems of the United States. The review of economic statistics, 18(3), 105-125. https://doi.org/10.2307/1927837

Miller, R. E., \& Blair, P. D. (2009). Input-output analysis: foundations and extensions. Cambridge university press.

Monarca, U., Cassetta, E., Re, M. L., \& Meleo, L. (2019). A network analysis of the intersectoral linkages between manufacturing and other industries in China and Italy. Global Journal of Emerging Market Economies, 11(1-2), 8097. https://doi.org/10.1177/0974910119871367

Newman, M. (2018). Networks. Oxford university press.

Pyatt G., \& Round, J. I. (1978). Accounting and fixed price multipliers in a social accounting matrix framework. The Economic Journal, 89(356), 850-873. https://doi.org/10.2307/2231503

Zhang, H., Chen, L., Tong, Y., Zhang, W., Yang, W., Liu, M., Liu, L., Wang, H., \& Wang, X. (2018). Impacts of supply and consumption structure on the mercury emission in China: An input-output analysis based assessment. Journal of Cleaner Production, 170, 96-107. https://doi.org/10.1016/j.jclepro.2017.09.139

Zhang, Y. (2017). Interregional carbon emission spillover-feedback effects in China. Energy Policy, 100, $138-148$. https://doi.org/10.1016/j.enpol.2016.10.012 